\title{
Impact of Service-Learning on Students Employability Skills: A Balanced Approach to Empower Meaningful Learning Experience
}

\author{
Muhd Khaizer Omar'1, Mas Nida Md Khambari², Aini Marina Ma'arof², Abu Bakar Razali ${ }^{3}$ \\ ${ }^{1}$ Department of Science and Technical Education, Faculty of Educational Studies, Universiti Putra Malaysia, UPM Serdang, \\ Selangor, Malaysia \\ ${ }^{2}$ Department of Foundations of Education, Faculty of Educational Studies, Universiti Putra Malaysia, UPM Serdang, Selangor, \\ Malaysia \\ ${ }^{3}$ Department of Language and Humanities Education, Faculty of Educational Studies, Universiti Putra Malaysia, UPM Serdang, \\ Selangor, Malaysia \\ Email: khaizer@upm.edu.my, khamasnida@upm.edu.my, ainimarina@upm.edu.my, abmr_bakar@upm.edu.my
}

How to cite this paper: Omar, M. K. Khambari, M. N. M., Ma'arof, A. M., \& Razali, A. B. (2022). Impact of Service-Learning on Students Employability Skills: A Balanced Approach to Empower Meaningful Learning Experience. Open Journal of Social Sciences, 10, 343-364.

https://doi.org/10.4236/jss.2022.102025

Received: December 10, 2021

Accepted: February 22, 2022

Published: February 25, 2022

Copyright (c) 2022 by author(s) and Scientific Research Publishing Inc. This work is licensed under the Creative Commons Attribution International License (CC BY 4.0).

http://creativecommons.org/licenses/by/4.0/

\begin{abstract}
The present study first defined service-learning and highlighted the research outcome from the organized service-learning project at the university. Meanwhile, the distinction between service-learning and volunteerism was also explored by applying the existing theoretical knowledge to practicalities, including how the two terminologies are different in identifying meaningful learning experiences of students involving more hands-on approaches. On a similar note, the concept of knowledge without practicality had been justified in past research whereby the transferable core skills were transmitted through the experiential learning of students for the purpose of developing employability skills. The objective of the current research was to investigate the impact of service learning in reciprocal processes on students and communities, particularly in regard to how these experiences can benefit the two parties based on the perspectives of the students. In regard to this matter, the current research carried out a case study on 15 postgraduate students who experienced service-learning project at Putra Future Classroom at the Faculty of Educational Studies, Universiti Putra Malaysia. More specifically, a specific project call "Earth Day" was organized in commemorating the annual earth day celebration around the world. The project involved children aged between four and six years old who experienced numerous activities related to earth day awareness campaign. As such, this paper analyzed the postgraduate students' feedbacks to investigate their experiences in organizing service-learning project. Apart from that, the researchers deemed that it was
\end{abstract}


important to assess the learning experiences from the theoretical knowledge obtained from the traditional classroom for the course Program Evaluation in Technical and Vocational Education and Training (TVE5006 and EDU5443). At the end of the service-learning project, the students were asked to answer an open-ended qualitative questionnaire disseminated on JotForm which an online questionnaire platform for the purpose of data collection is. All answers were recorded and later analyzed thematically using a two-layer constant comparative analysis method which was then triangulated with class assignments, observations, and students' reflections by way of journal entries. Finally, the current research examined the meaning and value of pragmatic education based on the concept of education as democracy for all as stated by John Dewey in order to redefine the curriculum for the $21^{\text {st }}$ century with the aim of making it more vibrant and promulgating "on-the job" training prior the employment of graduates.

\section{Keywords}

Experiential Learning, Skills-to-Work, Community-Based Learning, Volunteerism

\section{Introduction}

"When I get involved and serve in these programs, I am automatically subjected to being part of the community. This allows me to meet and learn from a range of new people and create memorable experience with others that will last a lifetime". The quotation depicts the overall experience of students after going through the meaningful service-learning project. According to the response given, it can be concluded that the respondent had a good reason for complementing the service-learning project, thus creating a positive perspective of immersion experience with the communities. In addition, it was revealed that service-learning promotes memorable experience that could never be forgotten. Meanwhile, the beautiful quotation remarks were intriguing as the respondent shared her narration as shown at the beginning of this paper. Therefore, the current research deemed it necessary to analyze the narrative from other participants who participated in the service-learning project.

The rudimentary aspect of service-learning has taken a major role in one educational experience especially in enhancing the curriculum to ensure that it becomes more attractive and interactive. More importantly, educators are aware of the importance to engage the students with both the industries and communities despite realizing that the element of service-learning has already been imposed in some of the curriculum and teaching content of the syllabus. Because of the lack industrial experience among students before venturing job market especially when it comes to synchronizing academic knowledge to hands-on practices, therefore, it is vital to ensure that educators are familiar with the component 
of service-learning considering that the premise of any teaching and learning environment is to ensure that the learning "happens".

On another note, academic content can only be practiced if the students venture into real-life environments that are able to facilitate them in transmitting the academic knowledge into practicalities. Hence, it is important for teachers to practice service-learning and the importance of delving into community service because they help to assist and bring effort in fulfilling the needs of community and simultaneously benefits the participants as they are able to apply the existing knowledge from the curriculum content and skills through a programmatic and structured service-learning project (Billig, 2011). Ultimately, the educational objective that is solely aligned with theoretical knowledge could be further enhanced into meaningful learning experience through the engagement with community in fulfilling the needs of surrounding grassroots with the aim of prospering the reciprocal learning between students and communities (Thomson, Smith-Tolken, Naidoo, \& Bringle, 2011).

Service-learning involves a total of four pillars in the process of structuring a project which include the service that addresses real life needs, the service and learning goals that are equally important, reciprocity between those serving and those being served, and a program that is clearly structured for participants (Chambers \& Lavery, 2012; Jacoby, 1996; Kaye, 2004; Schoenfeld, 2006; Scott, 2006). Service-learning is an experiential teaching method that combines instruction with community service in order to enrich students' academic learning, interpersonal skills, and sense of responsibility while making meaningful contributions to the community (Bassi, 2011). The accumulation of bilateral relationship between students and communities successfully strengthen mutual benefits. In addition, the students are provided with the opportunity to progressively practice and utilize their skills to gain a remarkable experience through the application of their knowledge to practicalities. On the other hand, the communities should maintain their connection with educational institutions because it is believed to be helpful in overcoming several issues such as the lack of infrastructure, education and tutorial services for kids, and opportunities in receiving technical advice on material or environmental and ecosystem stability.

Furthermore, it is important to note that service-learning has become the most preferable teaching method in several countries such as the United States, Australia, and the United Kingdom. In regard to this matter, many universities have adopted service-learning in their curriculum development whereby students will be given credit hours for the time spent organizing and participating in the service-learning activities. Hence, the present study primarily explores the impact of service-learning on Malaysian postgraduate students who were undertaking courses that were previously taught in traditional classroom setting. In this case, the postgraduate students delved into more natural settings of service-learning project that was created in accordance to the course content and tentative schedule. Moreover, the students were briefly explained about the clear 
distinction between service learning and volunteerism by connecting their course objectives to the service. Consequently, the partnership with the Family, Adolescent and Child Research Centre of Excellence (FACE), Universiti Putra Malaysia managed to be established to ensure that the service-learning is successful. A clear definition of the community adopted in the present study refers to children between the ages of four to six years old that participated in the service-learning project. More importantly, this helped to ensure a more positive outcome for the program theme which was Earth Day. Finally, the development of the partnership framework through purposeful communication with all partners is the key to a successful service-learning project.

\section{Literature Review}

\section{1) Service-learning: Prosper Meaningful Teaching and Learning Envi- ronment}

Service-learning has been studied over the past few years and has managed to attract a considerable amount of attention as a result of its contribution through the engagement of students with real-life settings. Most scholars suggested that service-learning has produced impactful application in assisting students to incorporate numerous factors that can contribute in enhancing the knowledge and skills of the students (Furco, 1996; Kuh, 2008). Apart from that, it can also help to close the gap between educational institutions and community surroundings. The exclusivity of university that represents the only university community receiving the necessary benefits is no longer a practical objective of universities. Hence, university plays an important role in outreaching the communities in order to disseminate knowledge and expertise with the aim of facilitating the advancement in technologies and knowledge sharing though the established relationship. On a similar note, the literature drives to offer several outcomes achieved by previous studies in regard to service-learning.

Accordingly, it is important to understand that there is a difference between service-learning and other community-based activities such as volunteerism, internship, and student outreach. While it is common to accommodate the term service-learning and volunteerism considering that they have been used interchangeably in research context. Nevertheless, the basis of service-learning and volunteerism under one definition is not accurate. According to Furco (1996), service-learning can be defined as "programs that are distinguished from other approaches to experiential education by their intention to equally benefit the provider and the recipient of the service as well as to ensure equal focus on both the service being provided and the learning that is occurring" (p. 5) based on the premise of service learning which is to integrate community services into academic content. National Service-Learning Clearinghouse (2005) defines service-learning as a teaching and learning strategy that accommodates a meaningful learning community services based on appropriate instructions that can further reflect rich learning experiences, community engagement, and civic respon- 
sibility principles. Meanwhile, the concept of service-learning has always been misinterpreted with volunteerism. Henderson (1984) clearly defined volunteerism as non-monetary orientation formed by individual who has the time and effort. Therefore, it is vital to understand that service-learning activities emphasize on the systematic integration between community service and academic knowledge considering the clear distinction between service-learning and volunteerism. On the other hand, volunteerism is described as a personal effort to offer assistance that comes in the form of energy and finance.

Recently, several past studies have depicted the effect of service-learning in the development of cognitive, affective, and ethical values of students as well as the reciprocal benefits that are transferred to the community which also create a positive relationship between participating students and communities (Astin \& Sax, 1998; Barth, Adomßen, Fischer, Richter, \& Rieckmann, 2014; Butin, 2006; Giles \& Eyler, 1998; Kendrick, 1996). Intentions to enrich the communities and to sustain progression of service-learning project seem to have successfully instilled the students with civic responsibilities, such as leadership skills and enhanced self-confidence (Barth, Adomßen, Fischer, Richter, \& Rieckmann, 2014; Sutheimer \& Pyles, 2011; Varty et al., 2011). Accordingly, service-learning enriches the entire learning experience of students by weighing the learning objective and service outcomes which consist of the mutual benefits between the students and communities. The deep learning is guided by the fundamental concept of subject matter whereby the theoretical knowledge and practical learning are combined to ensure a meaningful learning environment through the service-learning project (Bodorkós \& Pataki, 2009; Sutheimer \& Pyles, 2011). On a similar note, the outcomes from the planned activities are expected to promote the academic context and have been designed in such a way that both aspects of the service are able to enhance learning, which in turns allow the learning process to improve the service in an integrated way instead of merely acting as a supplementary activity.

The effect of service learning on the overall learning outcome becomes more profound considering its ability to permeate numerous benefits in the educational journey of students. In addition, several positive characteristics that are projected by service-learning include positive individual attitudes towards themselves, school and learning, civic engagement, social skills, and academic performance (Celio, Durlak, \& Dymnicki, 2011). Hence, this indirectly alleviates the majority of curriculum content by bringing out the voice of the community through their involvement in this relationship. Apart from that, it also reflects that the accumulation of service-learning by the students has become more applicable and prodigious in the learning environment of the 21st century. The book-based education encumbered the stagnant process of teaching and learning to inundate the existing theoretical knowledge. The research by Pless, Maak, and Stahl (2011) also found similar outcomes that depict service-learning empowerment in developing human capital by further listing out six areas, namely re- 
sponsible mind-set, ethical literacy, cultural intelligence, global mind-set, self-development, and community building. Apart from that, a number of processes were pointed out which facilitate learning at the cognitive, affective, and behavioural levels. On a more important note, the process of resolving cultural and ethical paradoxes, constructing a new life-world, developing new perspectives of self and the world, and making sense of the emotions experienced when on the assignment were also considered very important in the learning process of students.

Service-learning promotes numerous positive values in human beings as a way to expedite the common traits which include individual and collective efforts of people. In Yeh's (2010) and Chambers and Lavery's (2012) studies, they primarily discuss service learning in regard to the experience and reflection that take place during the activity. They stated that self-belonging felt towards a community as well as the effort made to counteract the lacking in the society are able to produce values that should be acquired strongly by the society well-beings in todays' world. Chamber and Lavery (2012) pointed out several values which include empathy, leadership, self and societal reflection, confidence, professional practice, and knowledge and skills. Meanwhile, Yeh (2010) emphasized the pivotal traits to ensure survival which include building skills and understanding, developing resilience, finding personal meaning, and developing critical consciousness, particularly not only as predictive human beings but also for the employment market. Overall, it is the time-saving facet of service-learning enables the students in the educational institutions to experience such valuable experiences which are believed to enrich their overall learning experiences.

Another salient indication towards promoting service-learning was discussed by Foli, Braswell, Kirkpatrick, and Lim (2014) to which they argued that the primary goal of service-learning in a project depicts the impotent role in building character values through the leadership role of participant. Moreover, the integration of service-learning into a leadership course is an effective approach that can develop leadership behaviours that are considered as the necessary skills-to-work in the $21^{\text {st }}$ century. On another note, service-learning participants are encouraged to engage with meetings and decision-making task, particularly when planning a project. This activity enriches the leadership role of students with innate in organization. Furthermore, service-learning surmises that each task has different role considering that some of the informants are given a cursory attention to the distribution of task; hence, the participant is required to act upon it in order to ensure the project is successful.

In all, a considerable amount of literature clearly stated that service-learning is immersed and has been widely practiced throughout universities despite the interchangeable terms of the practical approaches of service-learning which include community-based project, volunteerism, and internship. In addition, it is clear that the field of service-learning must have a clear distinction because any project has to undergo thorough theoretical knowledge which can be transferred 
to practical effort. This argument for inquiry on service learning, particularly its impact on their learning experience and ability to transfer from content knowledge to practice is very important to help the students to grow through a wide variety of meaningful learning experiences. In summary, it is extremely important to assist students to become better graduates by allowing them to acquire the necessary knowledge and skills because it is beneficial for employment purposes. Furthermore, the current society needs individuals with good qualities in order to embark the salient of citizenship role and human capital values.

\section{2) Theoretical Perspective}

Service-learning is an educational pedagogical approach derived from experiential learning theory. This theory was developed by John Dewey (1938) based on the following two principles: 1) the principle of continuity, and 2) the principle of interaction. The theory was further supported by Giles and Eyler (1994) who stated that the philosophy of Dewey is the main source for developing the theory of service-learning. The essence of service-learning is dependent on the philosophy of service and learning which occurs through experience, reflection, and civic engagement within the collaborative relationship among community partners (Flecky \& Gitlow, 2011). Furthermore, this approach allows the participants to reflect about themselves within the educational and community objectives in regard to the activities. Jacoby (2015) agreed that reflection is among the core elements of service-learning as proposed by Dewey. Hence, it is apparent that service and learning have to be balanced in order to create a meaningful experience. One of the theoretical foundations of service-learning is based on Kolb's (1984) Experiential Learning Model which comprises of four elements, namely concrete experience, observation of reflection on that experience, formation and synthesis of abstract concepts based on the reflection, and active experimentation that evaluates the concepts in new situations. Overall, the four elements form a cycle or spiral of learning as illustrated in Figure 1.

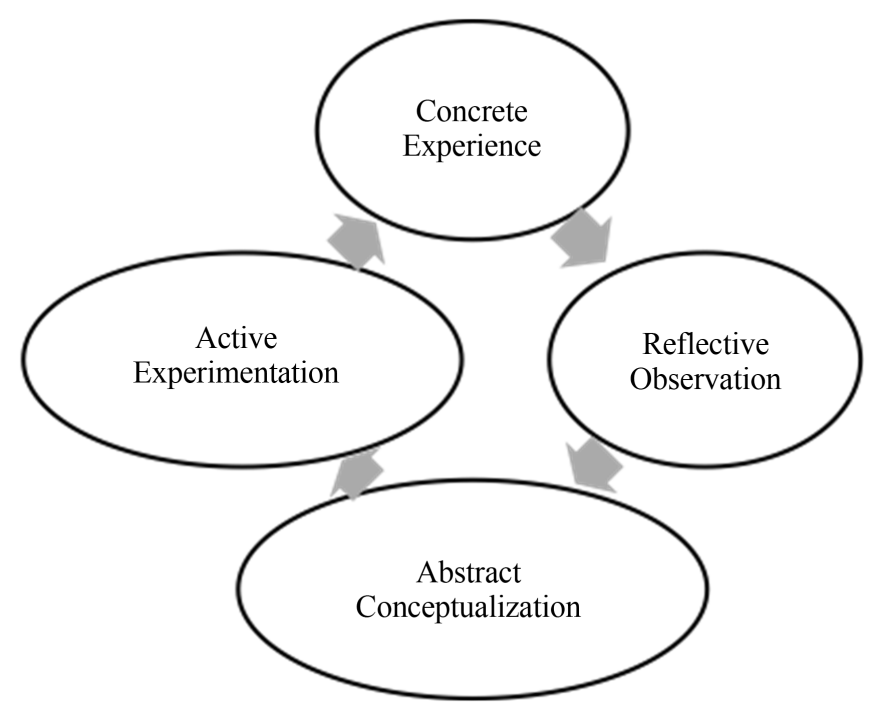

Figure 1. Experiential learning model, adapted from Kolb (1984). 
Generally, in this model, Kolb argues that participants can enter the cycle at any point, but service-learning is often designed to begin with concrete experience. Kolb (1984) stated that the process of learning starts with concrete experience because it enables the learners to test their newly developed or learned concepts prior to proceeding to other elements. Meanwhile, Jacoby (1996) stated that service-learning is a form of experiential education which requires students to be engaged in activities that address human and community needs together with a structured design that helps to promote the learning and development of students. Conversely, this is different from volunteerism and community service based on the explicit learning objectives which is to meet the driven needs of the community. Furco (1996) further postulated that volunteerism only provides service with no intention of reflecting and learning, whereas community service does not necessarily include reflection and may lack the academic content. Therefore, the misconception on service-learning with other forms of program will affect the learning goals of the participants and community needs.

\section{3) Research Purpose}

The purpose of the current research was to investigate the impact of service-learning project on postgraduate students' ability to transfer content knowledge to practice through the theoretical lens of Deweyan pragmatic and progressive education. The present study analysed the experiential learning that occurs from the service-learning activity by positioning it with his broader theory of progressive education, followed by the process of determining the reciprocal benefits gained by the students and communities from this experience. Ultimately, the researchers offer their take on the meanings and values of service-learning to the students at the university level, educators, and employers were considered by drawing the conclusions concerning the right decision making in the implementation of curriculum that is closely aligned with real-life environment (e.g. community and workplace) as well as understanding the important needs for future graduates to possess employability skills.

\section{Research Methods}

A qualitative study employing the case study approach was conducted for the present study. More specifically, an event (namely the Earth day program) that were organized in the community was studied, while the emerging themes that were influential in determining the effectiveness of the program were identified by way of analysing students' reflections, responses and reactions to this program especially in connecting to what they have learned in class with what they experienced in the program. The purpose of employing these qualitative data collection techniques was to elucidate the benefits of the program for future projection. In doing so, the postgraduate students' narratives from structured reflective-typed questions were collected and employed as the primary resources for data collection purposes. The data were derived from the class assignments, observations, and reflection notes provided by the students were subsequently 
utilized for the triangulation processes. These data were significant for the themes development and validated the qualitative findings.

\section{1) Research Context: The Service-learning Project (Earth Day)}

Earth Day at Putra Future Classroom was conducted for the purpose of inculcating positive attitude towards preserving the nature among children who have been previously exposed and taught about recycle. In addition, it is undeniable that recycling is an easy way for students to get involved in improving their local environment in addition to the fact that it is extremely beneficial. Apart from that, recycling saves energy, reduces raw material extraction, and combats climate change. A vast majority of studies agreed that recycling waste is better for the environment rather than incinerating or landfilling it. Hence, the knowledge about recycle has become vital to children as it seeks to lessen or reverse the negative behaviours that lead to the degradation of the environment. According to Porter (1997), children are of particular interest in environmental education because it is less likely that they have performed harmful environmental behaviours that need to be unlearned. Apart from that, they are provided with a longer period of time to learn about the environment, which in turns allow them to positively influence the environment. Furthermore, children can serve as agents that can encourage others to act in an environmentally responsible manner which can be translated to practical behaviour of the grassroots in such nations.

The younger generation especially today's students will be faced with numerous challenges in regard to environmental degradation. Hence, it is important to educate them on world issues to ensure that leadership and universal values can be nurtured. This approach can be a success by inculcating the values that can be learned in the daily life of the students, thus fostering civic behaviour as stated in Malaysia Education Blueprint 2013-2025: Preschool Pre-School to Post-Secondary Education (Ministry of Education Malaysia, 2013). Furthermore, fortifying environment-loving attitudes in the early stages of childhood is able to increase the civic values of society as well as facilitate the development and well-being of Malaysia as a developing country.

In line with the celebration of Earth Day 2018, Putra Future Classroom, Faculty of Educational Studies along with Family, Adolescent and Child Research Centre of Excellence (FACE) collaborated with the Faculty of Human Ecology with the aim of designing an interactive seminar to inculcate the awareness among the young generation, particularly in imparting the knowledge on the importance of preserving the environment with a consistent theme of ending plastic pollution.

This interactive seminar is one of the Putra Future Classroom's initiatives to develop an educational learning experience to the participants. The aim of Putra Future Classroom is to become an edutech-tourism attraction under Putra EduPark. In regard to this matter, Earth Day's celebration at Putra Future Classroom acts a test-run and simulation for educational content packages that will be made available to guests who visit Putra Future Classroom in the future. More- 
over, this package is the first package developed to provide an authentic experience of using Putra Future Classroom to the visitors. Apart from that, it is also a business of Putra Future Classroom to collaborate with the industry and the surrounding communities as well as to support the Malaysia Education Blueprint 2013-2025.

\section{2) Data Collection}

In this case study, a one-day program was conducted among children with the age ranging between four and six years old from the Family, Adolescent and Child Research Centre of Excellence (FACE), Universiti Putra Malaysia based on this service-learning project. Notably, the module was developed and utilized as the main service-learning content prior to the event. The program took place on April 20, 2018 (Friday) at Putra Future Classroom (PFC) and PFC Lounge, UPM involving around 60 individuals (30 preschool children and escort teachers, 25 postgraduate students of EDU5304 Instructional Media, TVE5006/EDU5443 Program Evaluation in Technical and Vocational Education and EPY5009 Thinking and Reasoning, 10 lecturers and technical staff of PFC and Infocomm Development Centre, iDEC).

In this study, a purposive sampling was carried out to choose students who were fit to be the participants of the survey. The population of this study consisted of postgraduate students from the Master of Education in Technical and Vocational Education program. More specifically, the students were enrolled in TVE5006/EDU5443, Program Evaluation in Technical and Vocational Education course from the Faculty of Educational Studies, Universiti Putra Malaysia (UPM). In the case of the current research, a structured open-ended reflective type of questionnaire was distributed to the students using an online platform called "JotForm" according to a designated time and timeline. The structured service-learning project reflection questions were adapted from Austin Community College District service-learning division which was accessible online. Simultaneously, the researchers also observed the service-learning environment of the students. Furthermore, field notes were taken during the observation in order to gain an initial understanding on how service-learning can enhance experiential learning of students that is carried out based on the job scope.

Particularly, the participants of the survey were chosen from educational-based courses taken at the faculty. In particular, a total of 15 students were asked to participate in the planning of the service-learning project along with other two courses that were handled by different researchers. Consequently, the students were required to develop a program (for three slots with different timeline) based on the Earth Day theme in order to ensure that the service-learning project is able to fulfill the objective of the program.

\section{Results and Findings}

The current research conducted a constant comparative analysis and carried out a triangulation process using data sets that were obtained from students' reflec- 
tion notes, class assignment, and field observation for the purpose of analysing the descriptive feedback of the participants. The analysis on the service-learning impact among postgraduate students was conducted based on several short close-ended questions distributed on an online platform known as JotForm. Next, all answers were downloaded from the JotForm database and transferred to Microsoft Excel, which were then analysed thematically using color-coded technique. In this case, two-layer data analysis was employed to determine the themes that emerged in the present study. Meanwhile, a peer-reviewed process was utilized to ensure that the saturation of the qualitative constant comparative analysis data is guaranteed. A total number of 15 participants were involved in the process of gathering the qualitative data. Finally, the quotations selected from the narrative feedback that have close influence with the themes' development were reported in this section.

\section{1) Reciprocal Benefits of Service-learning}

The thematic analysis revealed the positive influence on service-learning project from two different perspectives. First, students depict themselves as the recipient of the positive outcomes of the project, and second, they believe that there are impacts on participants after going through such experiences. In this case, a few excerpts portrayed the outcomes gained from the Earth Day project. For instance, informant 6 shared his/her thoughts regarding the experience of the overall process by stating that:

"Community gives a lot of positive effects on me, such as helping kids to understand about environment and recycle and making contacts with friends and lecture".

The service-learning project also had a few outcomes in terms of building a relationship and shared-knowledge about the subject matter. Similarly, informant 12 enunciated the element of giving back to the community through his or her role that managed to provide a positive impact to the recipients of the project by stating that:

"As one of the persons who can give awareness on how to save the earth and taking care of the nature."

Hence, this informant believed that the effort of service-learning actively provided him/her as a value added element in his/her learning experience. On another note, informant 7 emphasized that the outcome from the project would go beyond time and become an imposed-value that will be long-lasting by commenting that:

"I believe the children will practice all the knowledge about preserving our nature that they learnt during the programme to become more responsible adults in the future."

\section{2) Enriching Informal Learning}

The participants disclosed their satisfaction by stating the learning outcomes gained by the recipients of the project. In this case, the participants were asked a question on the best things that they discovered about the community with the aim of exploring the possible benefits from the project. Overall, it was regarded 
as a fruitful experience. Informant 7 stated the importance of preserving nature by having sustainability attitudes starting from the children exposure towards nature by proclaiming that:

"For the older generation, they actually have the knowledge about preserving nature but rarely practice it. The younger generation, they just love to learn new things and I hope they will practice it in the future. It is interesting to note that students flourish about the important to make the event happen by having full commitment and cooperative among team members. The best part is everyone tries their best to make the event work, and if something not right happen with their friends they will help"

Consequently, this narration was categorized as an informal learning because it went beyond traditional learning outcome that is more affective in nature. The team spirit enriched students' extrinsic values that are related to the important life and employment skills. The students who were assigned to give a talk during the program managed to learn new things from the children. The informant asserted his/her narrative in an excited way,

"They are so cute! They also are energetic and come with a lot of questions. Each of their questions is unexpected!"

It is important to note that through the researchers' observations of this event in the Earth Day program, it was observed that the children asked several questions that were beyond the knowledge of the postgraduate students, thus producing a challenging environment. While some of the questions were answered based on the prior experience of the postgraduate students and some came from existing information, some were quite challenging for them. This situation imposed some elements of surprise in order to encourage the critical thinking skills generated from informal learning for the postgraduate students. Moreover, this situation enriched the postgraduate students reflective skills to deal with questions from children in a fast pace.

\section{3) Instilling Knowledge and Experience}

The thematic analysis revealed the knowledge gained from the involvement in the service-learning project. On the premise of what was learned from the service-learning experience, the postgraduate students shared their overall experience which included governance and conflict that occurred throughout the process. One informant portrayed his or her frustration by stating that:

"Do not procrastinate in whatever we doing. Such as do not procrastinate in do revision for exam or do preparation in set up a program."

On another note, one of the students asserted his or her concern regarding the children. For instance, informant 30 pointed out his or her dispositions towards students as a result of his or her commitment in educating the positive values to the nation's younger generations:

"I learn the future is hold in the hand of the children today. So, inculcate them with good values and attitudes will help to create better generation."

The use of technology was employed in the service-learning project apart from the informal learning of the environment and the physical engagement 
with human interaction. Informant 8 depicted that he or she benefitted from the use technology and embarked the salient benefits of technology in ensuring the success of the program. In addition, the students were also introduced with the process of making assumptions and evaluation as part of their class assignment in indicating the effectiveness of the planned project. The informant asserted the following statement in portraying his or her experienced after joining this program:

"the learning for me is teaching using technology and evaluation through observation. This can be applying when I teach and evaluate people."

\section{4) Skills-to-Work}

One of the salient features in service-learning is the development of skills-to work. Service-learning has been proven as an effective platform for students to practice their skills which include hands on approaches as well as employability skills which are regarded as transferable core skills that are pivotal for employment market. A specific question was asked to explore what the students learned from the service-learning, particularly in the aspect of skills development. Informant 4 managed to develop his or her skills in developing soft skills traits which are one of the necessary employment skills in the 21 st century that was driven from the service-learning outcome:

"soft skills like communication and teamwork."

In another transcription, informant 7 supported the notion by stating that:

"I used my communication skill to share the information with the kids about preserving our nature and also get feedback from them about the programme."

In regard to this matter, students were given the opportunity to experience and learn to exercise effective communication for the purpose of thoroughly improving the better way to communicate with different audiences.

Meanwhile, informant 6 shared his or her thought on the participant of the service-learning project that consisted of the administrators, lecturers, officers, technical supports that the student had to deal with:

"effective communication to make sure everyone gets right information."

More importantly, the students had to instruct and constructed effective communication in order to send a clear message with the aim of ensuring that the program was successful. Other than that, they learned how to communicate with different stakeholders whereby the communication requires certain form of formality and protocol. On the premise that service-learning provides a platform to learn skills for employment, informant 8 demonstrated that:

"evaluation, observation, communication, cooperation and facilitation" as core skills learned though this project, projecting how service-learning has become powerful tool in projecting meaningful learning proficiency."

\section{5) Managing Conflicts and Appraising Efforts}

In this section, the participants were asked to share their frustration as well as what they valued the most during their participation in the program. According to their reflections, it can be understood that the participants were faced with a myriad of contingent scenarios which forced them to deal with various issues 
that required critical problem solving. The following question was asked to the participants: describe a person you've encountered in the community who made a strong impression on you, positive or negative. Informant 4 suggested the positive effect gained from the service-learning project that was developed through the collaborative learning and team spirit that ultimately contributed to commitment and intensity. He or she straightforwardly stated that:

"my teammates. Because their teamwork and commitments were really great. Even you did wrong, they still support and taught on how it would be done."

Meanwhile, another participant from the program pointed out his view on this matter:

"the person made a strong impression to me was a boy; he is cheerful and immersed himself in all the activities."

Hence, this provides a strong indication that the collaborative effort from the participant of the program empowered the motivation to ensure a successful completion of the program. Additionally, informant 13 praised the leadership style of his or her classmates through the following description:

"I think my leader has shown great impression to me as she manages to control the group well. She also has contributed a lot of time and money for the success of the program".

Furthermore, the findings were less attractive if some of the situations and conflicts that occurred during the program were not adequately elaborated. Hence, the participants were asked to share any disappointment or success of the project as well as some reflections pertaining to such situation. As a result, a total of four issues that supported the descriptions managed to be determined which include sponsorship, cooperation, time, and preparation. Informant 3 was anomaly as he or she had a salient reflection based on his or her experience conducting the project by stating that:

"to be more patient in doing something and be willing to accept reprimand."

At one time, an informant praised his or her team by projecting the success of the project was the result of the team work and cooperation of the team members,

"I think our project learnt smoothly because of full cooperation of every one that involves organising this event. I have learnt that the success of the project depends on cooperation level of the members that organise the project."

Interestingly, the participants also shared about the difficulties they faced when conducting the project. Informant 8 and 14 respectively shared the following important notions:

"the disappointments of the project were the reaction of my project was underwhelming and I believed it can be better" and "my disappointment is when we can't get enough sponsorship although at first, $P$ ve been told, we already have the sponsorships. I learn that, when we need to join others group, we need to prepare for any problems that might be happened."

6) Values-driven 
In this case, those who collaborated and participated were assigned with an important role in service-learning which usurped the intrinsic and extrinsic values from service-learning activities. The values required the corroboration of the learning outcomes from the participants, particularly in terms of knowledge, skills, and attitudes that shape the holistic characteristics of the students. The overall experience of the students was shared in the narrative form based on the stated question which required them to complete the following sentence: Because of my program, I am... Informant 3 believed that service-learning has successfully improved his character to "be more positive and patient", while informant 10 and informant 14 respectively shared their fruitful indication that service-learning encouraged them to practice their

"responsibility towards any kind of injury, misunderstanding, etc. during the programme" and "become more responsible towards my group members and I learn that, we become stronger when we work in a team."

Overall, it can be concluded that these characteristics managed to be established naturally from the process of service-learning collectively. On the other hand, informant 8 shared his or her thought that service-learning activity is a platform for him or her to be "able to use the skills learned in classroom into practical experience". The outcome obtained from the service-learning was also in the form of motivation factors to the participants. Informant 8 asserted that:

"because of my program, I am become stronger and can face any challenge towards the future! portraying his feelings after completing the service-learning project."

\section{Discussion}

Dewey (1944) argued that education must stand on social interaction because the interaction between groups of people has profoundly become the ideal of knowledge to ensure that learning happens. Overall, it can be concluded that the pragmatic approach of education which promotes learning through experience is vital, while service-learning has become the tool to transmit this idea. In this regard, the findings of the present study were significant because it provided an enhanced understanding on Dewey's concept of pragmatic approach in education as well as the essentiality of interaction and communication in teaching and learning paradoxes.

Furthermore, the benefits of service-learning were proven/justified as it brought out contextual learning through servicing others by embedding that the concept of theoretical learning in the classroom tends to enrich the meaning making process through practical works. The conditions of service-learning that bring actual employment environment prosper students' skill-to-work. More importantly, service-learning has connected educational institutions and industries in powerful ways as well as closed the barrier of the imbalance of job market. On another note, the various combinations of service-learning activities required in today's job market tend to affect the way that the students can obtain 
all the necessary skills. In particular, this includes academic performance (GPA, writing skills, critical thinking skills), values (commitment to activism and to promoting racial understanding), self-efficacy, leadership (leadership activities, self-rated leadership ability, interpersonal skills), choice of a service career, and plans to participate in service after college (Astin, Vogelgesang, Ikeda, \& Yee, 2000).

Furthermore, several situations of excitement which involved the postgraduate students and recipients managed to be observed in detail during the activities conducted by the postgraduate students during the Earth Day program. The children as recipients successfully constructed a myriad of knowledge and skills after delving into the service-learning program. On a more important note, the students were able to deliver the content knowledge to the children in the simplest and understandable ways, and at the same time, managed to control the behaviour and tantrum of some children throughout the program which further promoted their patience and civic responsibility. Overall, that this type of community service allows the students to become active learners by bringing the skills and information from community work and integrating them with the theory and curriculum of the classroom in order to produce new knowledge (Mitchell, 2008), thus empowering them to venture into a new teaching and learning environment.

In this study, the postgraduate students were given more than eight weeks to prepare for the program. The students managed to prepare a meaningful teaching and learning content for the recipient through a fortuitous and ad-hoc task. Subsequently, the students were given guidance, advice and suggestions to meet the objective of the program. More importantly, this enforced the students to practice professional communication with the group of people considering that they were dedicated to the planned service-learning and the entire interaction that took place which included some of the high-level rank officers, dean of the faculties, and teachers. Apart from that, the students learned to create a bond and rapport despite their first encounter of such situation which further promotes the impact of service-learning. The knowledge and skills to deal with such situation is something that they cannot obtain merely from reading a book or attending classes, as it is more meaningful and impactful if experienced. It is important for them to delve in and venture it by themselves in order to gain a meaningful and beneficial experience. The service learning program enriched their learning experience that is might be helpful for their future employment.

One of the major points in service-learning courses is the implicit assumption to reach a wider community by providing service and knowledge that is regarded as a reciprocal process for both the students and recipients of the program (Blouin \& Perry, 2009). In this case study, it was possible that the most important element in the service-learning project was the interaction between students and children. The scenario in which the students had to handle and control the active children, and at the same time, deliver the course content in 
such uncontrolled situation was commendable. In controlling a hectic situation, the postgraduate students managed to share their knowledge on handling the tantrum of the children, excitement that aroused from the activities, and children who work independently. A set of skills was developed from this process which included several multicultural skills such as empathy, patience, attachment, reciprocity, trust, and respect (Einfeld \& Collins, 2008), particularly when interacting with their clients.

On another note, it is crucial for future workforce skills in preparing the students for future employment based on prediction and predictable measure. Basten, Evers, Geijsel, and Vermeulen (2018) discussed the challenges and strategies to overcome the lack of skills of future workforce by suggesting the needs of communication skills, social and cultural skills, creativity, critical thinking, problem solving, media wisdom, self-regulation, and collaboration in fulfilling the demand of $21^{\text {st }}$ century workforce skills in the existing environment and foreseeable future. This finding is in line with the study of Van Laar, Van Deursen, Van Dijk, and De Haan (2017) which established seven core skills: technical, information management, communication, collaboration, creativity, critical thinking, and problem solving. Apart from that, there are five contextual skills that manage to be identified, namely ethical awareness, cultural awareness, flexibility, self-direction, and lifelong learning. Nevertheless, it should be understood that all the skills are not limited to producing positive changes in academic, personal, social, and citizenship outcomes (Conway, Amel, \& Gerwien, 2009) because it can also be entirely practiced and transmitted into service-learning activity. Overall, service-learning does not only enrich the total ways of grasping the skills for employment but also strengthen the theoretical content that can be transferred to myriad environment and conditions. several situations of excitement which involved the perspectives of both the students and recipients managed to be observed in greater detail during the activities conducted by a few of the proactive students. The children as recipients successfully constructed myriad knowledge and skills after delving into the agenda of the service-learning program. On a more important note, the students were given the task to deliver the content knowledge to the children in the simplest and understandable ways, and at the same time, having to control the behaviour and tantrum of some children throughout the program which further promoted their patience and civic responsibility. Overall, it is undeniable that this type of community service allows the students to become active learners by bringing the skills and information from community work and integrating them with the theory and curriculum of the classroom in order to produce new knowledge (Mitchell, 2008), thus empowering them to venture into a new teaching and learning environment.

In the case of the present study, the students were given more than eight weeks to prepare for the program. The students managed to prepare a meaningful teaching and learning content for the recipient through a fortuitous and ad-hoc task. Subsequently, the students were complimented and given advice 
and suggestions to enhance the objective of the program. More importantly, this enforced the students to practice harmonious and professional communication with the group of people considering that they were dedicated to the planned service-learning and the entire interaction that took place which included some of the high-level rank officers, dean of the faculties, and teachers. Apart from that, the students learned to create a bond and rapport despite their first encounter of such situation which further promotes the beauty of service-learning. The knowledge and skills to deal with such situation is something that they can retrieve from a book; however, it is important for them to delve in and venture it by themselves in order to gain a meaningful and beneficial experience. The know-how ambience enriched their learning experience that is definitely helpful for their future employment once they graduated from the program.

A few insights that were impressive and astonishing managed to be discovered from the service learning activities. In this case, it referred to the involvement of community, particularly the kids and teachers who gave 100 percent commitment to the program. Indeed, one of the major attracting points in service-learning courses is the implicit assumption to reach a wider community by providing service and knowledge that is regarded as a reciprocal process for both the students and recipients of the program (Blouin \& Perry, 2009). In this case, it was possible that the greatest moment that took place during the service-learning project was the interaction between students and children. The scenario in which the students had to handle and control the active children, and at the same time, deliver the course content in such uncontrolled situation was remarkable. Fortunately, with the help of teaching and learning in regard to controlling a hectic situation, the students managed to share their knowledge on handling the tantrum of the children, excitement that aroused from the activities, and children who work independently. A set of skills was developed from this process which included several multicultural skills such as empathy, patience, attachment, reciprocity, trust, and respect (Einfeld \& Collins, 2008), particularly when interacting with their clients.

On another note, it is crucial to project the future workforce skills in preparing the students for future employment based on prediction and predictable measure. The employability skill, for example, is a crucial agenda in service-learning application (Omar et al., 2018). In response to this matter, Basten, Evers, Geijsel, and Vermeulen (2018) discussed the challenges and strategies to overcome the lack of skills of future workforce by suggesting the needs of communication skills, social and cultural skills, creativity, critical thinking, problem solving, media wisdom, self-regulation, and collaboration in fulfilling the demand of 21st century workforce skills in the existing environment and foreseeable future. This finding is in line with the study of Van Laar, Van Deursen, Van Dijk, and De Haan (2017) which established seven core skills: technical, information management, communication, collaboration, creativity, critical thinking, and problem solving. Apart from that, there are five contextual skills that manage to be identified, namely ethical awareness, cultural awareness, flexibility, 
self-direction, and lifelong learning. Nevertheless, it should be understood that all the skills are not limited to producing positive changes in academic, personal, social, and citizenship outcomes (Conway, Amel, \& Gerwien, 2009) because it can also be entirely practiced and transmitted into service-learning activity. Overall, service-learning does not only enrich the total ways of grasping the skills for employment but also strengthen the theoretical content that can be transferred to myriad environment and conditions.

\section{Conclusion}

This article offers an understanding knowledge creation through service-learning activities as well as how this activity could create belongingness and benefit both parties, especially from the postgraduate students' perspectives in the Malaysian tertiary education setting. Service-learning encapsulates livable learning experiences which ultimately explore a meaningful learning environment. In addition, such a program (i.e., service-learning) is important to transition from the stagnant process of conventional teaching and learning methods to something that focuses more on experiential and hands-on fieldwork. On a more important note, postgraduate students are faced with many challenges in their professional lives, such as unemployment. Hence, the shift in curriculum that is more grounded to the reality of surroundings must be taken into consideration for educational practice. In this case, service-learning is capable to connect the university and community in harmonious ways by offering a real-life experience and fieldwork practice. Furthermore, the possibility of embedding service-learning into the curriculum content of university courses will create a new and effective method in teaching and learning. Therefore, it is high time for service-learning which can be realized through experiential learning to take place in the field of postgraduate education. Finally, the involvement of postgraduate students and communities are able to benefit both parties in transfer of knowledge and skills in creating and extracting efforts that are needed by the community.

\section{Acknowledgements}

The assistance and involvement of the faculty members and staffs at the Family, Adolescent and Child Research Centre of Excellence (FACE), Faculty of Human Ecology, the Putra Future Classroom (PFC), and INNOVATE at the Faculty of Educational Studies, Universiti Putra Malaysia are greatly appreciated.

\section{Conflicts of Interest}

The authors declare no conflicts of interest regarding the publication of this paper.

\section{References}

Astin, A. W., \& Sax, L. J. (1998). How Undergraduates Are Affected by Service Participation. Journal of College Student Development, 39, 251-263. 
Astin, A. W., Vogelgesang, L. J., Ikeda, E. K., \& Yee, J. A. (2000). How Service Learning Affects Students. https://digitalcommons.unomaha.edu/slcehighered/144/

Barth, M., Adomßent, M., Fischer, D., Richter, S., \& Rieckmann, M. (2014). Learning to Change Universities from within: A Service-Learning Perspective on Promoting Sustainable Consumption in Higher Education. Journal of Cleaner Production, 62, 72-81. https://doi.org/10.1016/j.jclepro.2013.04.006

Bassi, S. (2011). Undergraduate Nursing Students' Perceptions of Service-Learning through a School-Based Community Project. Nursing Education Perspectives, 32, 162-167. https://doi.org/10.5480/1536-5026-32.3.162

Basten, F., Evers, A., Geijsel, F., \& Vermeulen, M. (2018). 21st Century Leadership Skills for Learning Networks at School. In International Conference for School Effectiveness and Improvement.

Billig, S. H. (2011). Making the Most of Your Time: Implementing the K-12 Service-Learning Standards for Quality Practice. The Prevention Researcher, 18, 8-14. https://doi.org/10.1037/e518012011-003

Blouin, D. D., \& Perry, E. M. (2009). Whom Does Service Learning Really Serve? Community-Based Organizations' Perspectives on Service Learning. Teaching Sociology, 37, 120-135. https://doi.org/10.1177/0092055X0903700201

Bodorkós, \& Pataki, G. (2009). Linking Academic and Local Knowledge: Community-Based Research and Service Learning for Sustainable Rural Development in Hungary. Journal of Cleaner Production, 17, 1123-1131. https://doi.org/10.1016/j.jclepro.2009.02.023

Butin, D. W. (2006). The Limits of Service-Learning in Higher Education. Review of Higher Education, 29, 473-498. https://doi.org/10.1353/rhe.2006.0025

Celio, C. I., Durlak, J., \& Dymnicki, A. (2011). A Meta-Analysis of the Impact of Service-Learning on Students. The Journal of Experiential Education, 34, 164-181. https://doi.org/10.1177/105382591103400205

Chambers, \& Lavery, S. (2012). Service-Learning: A Valuable Component of Pre-Service Teacher Education. The Australian Journal of Teacher Education, 37, 128-137. https://doi.org/10.14221/ajte.2012v37n4.2

Chambers, D., \& Lavery, S. (2017). Introduction to Service-Learning and Inclusive Education. In Service-Learning (Vol. 12, pp. 3-19). Emerald Publishing Limited. https://doi.org/10.1108/S1479-363620170000012001

Conway, J. M., Amel, E. L., \& Gerwien, D. P. (2009). Teaching and Learning in the Social Context: A Meta-Analysis of Service Learning's Effects on Academic, Personal, Social, and Citizenship Outcomes. Teaching of Psychology, 36, 233-245. https://doi.org/10.1080/00986280903172969

Dewey, J. (1938). The Theory of Inquiry. Holt, Rinehart \& Wiston.

Dewey, J. (1944). Democracy and Education: An Introduction to the Philosophy of Education. Text-Book Series in Education, Free Press.

Einfeld, A., \& Collins, D. (2008). The Relationships between Service-Learning, Social Justice, Multicultural Competence, and Civic Engagement. Journal of College Student Development, 49, 95-109. https://doi.org/10.1353/csd.2008.0017

Flecky, K., \& Gitlow, L. (2010). Service-Learning in Occupational Therapy Education. Jones \& Bartlett Learning.

Foli, Braswell, M., Kirkpatrick, J., \& Lim, E. (2014). Development of Leadership Behaviors in Undergraduate Nursing Students: A Service-Learning Approach. Nursing Education Perspectives, 35, 76-82. https://doi.org/10.5480/11-578.1 
Furco, A. (1996). Service-Learning: A Balanced Approach to Experiential Education. Service Learning, General, No. 128.

Giles Jr., D. E., \& Eyler, J. (1994). The Theoretical Roots of Service-Learning in John Dewey: Toward a Theory of Service-Learning. Michigan Journal of Community Service Learning, 1, 77-85.

Giles, D. E., \& Eyler, J. (1998). A Service Learning Research Agenda for the Next Five Years. New Directions for Teaching and Learning, 1998, 65-72. https://doi.org/10.1002/tl.7308

Henderson, K. (1984). Vollinteerism as Leisure. Nonprofit and Voluntary Sector Quarterly, 13, 55-63. https://doi.org/10.1177/089976408401300106

Jacoby, B. (1996). Service-Learning in Higher Education: Concepts and Practices (1st ed.). Jossey-Bass Publishers.

Jacoby, B. (2014). Service-Learning Essentials: Questions, Answers, and Lessons Learned. John Wiley \& Sons.

Jacoby, B. (2015). Taking Campus-Community Partnerships to the Next Level through Border-Crossing and Democratic Engagement. Michigan Journal of Community Service Learning, 22, 140-147.

Kaye, C. B. (2004). The Complete Guide to Service Learning: Proven, Practical Ways to Engage Students in Civic Responsibility, Academic Curriculum, \& Social Action. Free Spirit Publishing.

Kendrick Jr., J. R. (1996). Outcomes of Service-Learning in an Introduction to Sociology Course. Michigan Journal of Community Service Learning, 3, 72-81.

Kolb, D. A. (1984). Experiential Learning: Experience as the Source of Learning and Development. FT Press.

Kuh, G. D. (2008). Excerpt from High-Impact Educational Practices: What They Are, Who Has Access to Them, and Why They Matter. Association of American Colleges and Universities, 14, 28-29.

Ministry of Education Malaysia (2013). Preliminary Report Malaysia Education Blueprint (2013-2025).

https://www.moe.gov.my/menumedia/media-cetak/penerbitan/dasar/1207-malaysia-ed ucation-blueprint-2013-2025/file

Mitchell, T. D. (2008). Traditional vs. Critical Service-Learning: Engaging the Literature to Differentiate Two Models. Michigan Journal of Community Service Learning, 14, 50-65.

National Service-Learning Clearinghouse (2005). http://www.servicelearning.org/

Omar, M.K., Khambari, M. N. M., Ma’arof, A. M., Ismail, I. A., Kamalden, T. F. T., Jalil, H. A., Salim, S. S., Rahim, N. A. A., Alias, S. N., Puad, M. H. M., Muhamad, M. M., \& Arshad, M. M. (2018). Developing Employability Skills from Service-learning Experience at Putra Future Classroom (PFC). International Journal of Academic Research in Business and Social Sciences, 8, 472-790. https://doi.org/10.6007/IJARBSS/v8-i12/5046

Pless, N. M., Maak, T., \& Stahl, G. K. (2011). Developing Responsible Global Leaders through International Service-Learning Programs: The Ulysses Experience. Academy of Management Learning \& Education, 10, 237-260.

Porter, L. R. (1997). Creating the Virtual Classroom: Distance Learning with the Internet. John Wiley \& Sons, Inc.

Schoenfeld, R. (2006). Service Learning: Bringing together Students, Parents, and Community to Create a Better World. New Horizons for Learning. 
Scott, G. V. (2006). Incorporating Service Learning into Your Special Education Classroom. Intervention in School and Clinic, 42, 25-29. https://doi.org/10.1177/10534512060420010401

Sutheimer, S., \& Pyles, J. (2011). Integrating Sustainability and Service Learning into the Science Curriculum. In Social Responsibility and Sustainability: Multidisciplinary Perspectives through Service Learning (pp. 21-34). Stylus Publishing Sterling.

Thomson, Smith-Tolken, A. R., Naidoo, A. V., \& Bringle, R. G. (2011). Service Learning and Community Engagement: A Comparison of Three National Contexts. VOLUNTAS: International Journal of Voluntary and Nonprofit Organizations, 22, 214-237. https://doi.org/10.1007/s11266-010-9133-9

van Laar, van Deursen, A. J. A. ., van Dijk, J. A. G. ., \& de Haan, J. (2017). The Relation between 21st-Century Skills and Digital Skills: A Systematic Literature Review. Computers in Human Behavior, 72, 577-588. https://doi.org/10.1016/j.chb.2017.03.010

Varty, A. K., Lishawa, S. C., \& Tuchman, N. C. (2011). Sustainability Education through an Interdisciplinary and Service-Learning Approach. In T. McDonald (Ed.), Social Responsibility and Sustainability: Multidisciplinary Perspectives through Service Learning (pp. 35-60). Stylus Publishing.

Yeh, T. L. (2010). Service-Learning and Persistence of Low-Income, First-Generation College Students: An Exploratory Study. Michigan Journal of Community Service Learning, 16, 50-65. 